\title{
SOBREVIVÊNCIA E CRESCIMENTO DE MUDAS CLONAIS DE EUCALIPTO EM RESPOSTA À APLICAÇÃO DE FERTILIZANTE ORGÂNICO
}

\author{
Sula Janaína de Oliveira Fernandes ${ }^{1}$, Miranda Titon², Reynaldo Campos Santana ${ }^{3}$, Lucas Guimarães Antonini ${ }^{4}$, \\ Gilciano Saraiva Nogueira ${ }^{5}$, Nairam Félix de Barros Filho ${ }^{6}$
}

(recebido: 7 de outubro de 2009; aceito: 22 de agosto de 2011)

RESUMO: Conduziu-se este trabalho, com o objetivo de avaliar o efeito da aplicação de Fert-Bokashi® sobre a sobrevivência e crescimento de mudas de dois clones de Eucalyptus urophylla propagados pela técnica de miniestaquia. O experimento foi conduzido por um período de 28 dias, utilizando um delineamento experimental em blocos casualizados com três repetições, no esquema fatorial 6 x 2, sendo seis concentrações de Fert- Bokashi ${ }^{\circledR}(0,0 \%, 0,1 \% ; 0,3 \%$ : 0,5\%; 0,7\% e 0,9\%) e dois clones. Avaliou-se a sobrevivência das mudas, o crescimento em altura e a matéria seca da parte aérea, das raízes e total. Os resultados obtidos demonstraram que o Fert-Bokashi ${ }^{\circledR}$ não exerceu efeito significativo sobre a sobrevivência e o crescimento das mudas dos dois clones de Eucalyptus urophylla.

Palavras-chave: Eucalyptus urophylla, Fert- Bokashi®, adubação orgânica.

\section{SURVIVAL AND GROWTH OF EUCALYPTS CLONES SEEDLINGS IN RESPONSE TO ORGANIC FERTILIZER APPLICATION}

\begin{abstract}
This work aimed to evaluate the effect of Fert-Bokashi ${ }^{\circledR}$ on survival and seedlings growth of two Eucalyptus urophylla clones propagated by minicutting technique. The experiment was conducted over a period of 28 days using a randomized block design and three replicates in an $6 x 2$ factorial arrangement, with six Fert-Bokashi ${ }^{\circledR}$ concentrations $(0.0 \%, 0.1 \%, 0.3 \%, 0.5 \%, 0.7 \%$ and $0.9 \%$ ) and two clones. Seedlings survival, height growth and shoot, root and total dry matter were evaluated. Experimental results demonstrated no significant effect of Fert-Bokashi ${ }^{\circledR}$ on survival and seedlings growth of two Eucalyptus urophylla clones.
\end{abstract}

Key words: Eucalyptus urophylla, Fert-Bokashi ${ }^{\circledR}$, organic fertilization.

\section{INTRODUÇÃO}

No plantio de espécies arbóreas, a qualidade da muda é fundamental para alcançar os objetivos almejados, pois pode influenciar o crescimento, interferindo na produtividade das florestas.

A produção de mudas clonais de eucalipto empregando-se as técnicas de miniestaquia e microestaquia possibilitou ganhos em função do maior índice de enraizamento, menor tempo para a formação das mudas e maior uniformidade dos plantios. O uso dessas técnicas pela maioria das empresas do setor florestal brasileiro representa a aplicação de conhecimentos relacionados ao gradiente de maturação e de rejuvenescimento no processo de produção de mudas, em que ganhos em fase de viveiro com a utilização de propágulos mais juvenis estão bem evidenciados (ASSIS, 1997; TITON et al., 2003a,b, 2006; XAVIER; COMÉRIO, 1996; XAVIER et al., 2001).

$\mathrm{O}$ adequado manejo do minijardim clonal, a coleta e o enraizamento das miniestacas são essenciais para garantir a boa formação inicial das mudas clonais. Os rigorosos controles da fertirrigação, de pragas e de doenças nas diferentes fases do processo de produção de mudas garantem a qualidade das mesmas no viveiro, possibilitando o bom desempenho inicial no campo. O conhecimento da fisiologia da espécie, associada à função de cada nutriente é um fator de suma importância para se obter sucesso na nutrição das mudas.

\footnotetext{
${ }^{1}$ Engenheira Florestal-Mestre em Produção Vegetal-Universidade Federal dos Vales do Jequitinhonha e Mucuri/UFVJM-39100-000-Diamantina, MGsulafernandes@hotmail.com

${ }^{2}$ Engenheira Florestal - Professora Dra. em Ciência Florestal - Departamento de Engenharia Florestal - Universidade Federal dos Vales do Jequitinhonha e Mucuri/UFVJM - 39100-000 - Diamantina, MG - titonmiranda@yahoo.com.br

${ }^{3}$ Engenheiro Florestal - Professor Dr. em Solos e Nutrição de Plantas - Departamento de Engenharia Florestal - Universidade Federal dos Vales do Jequitinhonha e Mucuri/UFVJM - 39100-000 - Diamantina, MG - silviculturaufvjm@yahoo.com.br

${ }^{4}$ Engenheiro Florestal, Coordenador de Operações da Ekoflorestal - 38408-372 - Uberlândia, MG - floresteiroantonini@yahoo.com.br

${ }^{5}$ Engenheiro Florestal, Professor Dr. em Ciência Florestal - Departamento de Engenharia Florestal - Universidade Federal dos Vales do Jequitinhonha e Mucuri/UFVJM - 39100-000 - nogueirags@yahoo.com.br

${ }^{6}$ Engenheiro Florestal, Doutorando em Solos e Nutrição de Plantas - Departamento de Solos/DPS - Universidade Federal de Viçosa/UFV - 36571-000 Viçosa, MG - nairamf@yahoo.com.br
}

Cerne, Lavras, v. 17, n. 4, p. 601-606, out./dez. 2011 
Na propagação clonal por miniestaquia, a primeira fase em viveiro, após o estaqueamento, é o enraizamento das miniestacas que dura, em média, 30 dias (15 dias na casa de vegetação e 15 dias na casa de sombra). Em geral, as mudas recebem adubação de base e de cobertura. A adubação de cobertura inicia-se na casa de sombra, quando a muda direciona a maior parte de seu metabolismo para a expansão da área foliar e para a formação de raízes. Após esse procedimento, as mudas seguem para a fase de aclimatação, em que a demanda de nutrientes é maior em função do rápido crescimento. Depois de 70 a 80 dias, as mudas já são destinadas para o plantio em campo (ALFENAS et al., 2004).

Mesmo com expressivo avanço tecnológico obtido nos últimos anos, ainda não se chegou ao enraizamento de $100 \%$ na produção de mudas de eucalipto. Isso se deve, além dos fatores genéticos e de maturação dos propágulos, aos fatores externos que interferem no processo de produção. As falhas de enraizamento refletem diretamente no retorno econômico da Empresa.

Quanto à Agricultura Orgânica, também chamada de biológica ou alternativa, esta começou a se estruturar nas primeiras décadas do século passado. A partir dos anos 60 acelerou seu crescimento nos países desenvolvidos, fruto da preocupação com o impacto das técnicas agrícolas sobre a qualidade dos alimentos e do meio ambiente (KHATOUNIAN et al., 1996).

O composto fermentado Bokashi é uma mistura de diversos tipos de matéria orgânica farelada, submetida à fermentação, predominantemente do tipo láctica. $\mathrm{O}$ processo é de origem japonesa e foi desenvolvido e adaptado por Teruo Higa, na Universidade de Ryukyus (Okinawa, Japão), em 1980, e trazido ao Brasil pela Fundação Mokiti Okada, onde já é bem difundido, principalmente entre os agricultores nipo-brasileiros e entre os praticantes de agricultura natural. Em geral, a fermentação do Bokashi é obtida utilizando-se uma suspensão de microrganismos (HOMMA, 2005). O uso desses microorganismos visa a acelerar o processo de compostagem e, além disso, reequilibrar a população microbiana do solo (TRANI et al., 2006).

O Fert-Bokashi ${ }^{\circledR}$, produto agronômico à base de nitrogênio e carbono orgânico, tem sido utilizado em muitas pesquisas com culturas agronômicas, apresentando efeito positivo sobre as mesmas (BOTREL et al., 2007; GOMES et al., 2007; TRANI et al., 2006). Além disso, outros estudos vêm relacionando a aplicação deste com a produção de fungos micorrízicos arbusculares em espécies de citrus (HOMMA, 2005). A recomendação para a aplicação foliar do Fert-Bokashi ${ }^{\circledR}$ consiste em pulverizar, em concentração de $0,5 \%$ no período mais fresco do dia, sendo a frequência diferenciada para cada espécie.

Para as espécies florestais os estudos relacionados com fertilizantes orgânicos na produção de mudas ainda são incipientes, tornando-se de suma importância que seus benefícios sejam avaliados para as diferentes espécies. Assim, neste trabalho, objetivou-se avaliar o efeito da aplicação de Fert-Bokashi ${ }^{\circledR}$ sobre a sobrevivência e crescimento de mudas de dois clones de Eucalyptus urophylla propagados pela técnica de miniestaquia.

\section{MATERIAL E MÉTODOS}

O trabalho foi realizado no mês de maio de 2008, no viveiro clonal da Empresa Plantar Reflorestamentos S.A., localizada no município de Curvelo - MG. Foram utilizados dois clones de Eucalyptus urophylla (S.T. Blake) comerciais da empresa (Clone 1 e Clone 2), propagados pela técnica de miniestaquia.

Miniestacas apicais com 6 a $8 \mathrm{~cm}$ de comprimento foram coletadas no minijardim clonal e estaqueadas em tubetes de polietileno de $55 \mathrm{~cm}^{3}$ de capacidade volumétrica. Utilizou-se substrato composto por $20 \%$ de fibra de coco, $40 \%$ de casca de arroz, $40 \%$ de vermiculita, com a seguinte adubação de base no substrato: $2,4 \mathrm{~kg}$ por $\mathrm{m}^{3}$ de fertilizante de liberação lenta (garantias do fertilizante - $13 \%$ de $\mathrm{N} ; 6 \%$ de $\mathrm{P}_{2} \mathrm{O}_{5} ; 16 \%$ de $\mathrm{K}_{2} \mathrm{O} ; 1,4 \%$ de $\mathrm{Mg} ; 10 \%$ de $\mathrm{S} ; 0,26 \%$ de Fe; $0,02 \%$ de B; $0,05 \%$ de $\mathrm{Cu} ; 0,06 \%$ de $\mathrm{Mn} ;$ e $0,015 \%$ de $\mathrm{Mo}$ ).

A aplicação do Fert-Bokashi ${ }^{\circledR}$ foi realizada durante a permanência das miniestacas na casa de vegetação. Foram realizadas aplicações de $3 \mathrm{em} 3$ dias, durante 13 dias a partir do estaqueamento, por meio de um pulverizador costal, totalizando 4 aplicações. A umidade na casa de vegetação no período de condução do experimento foi superior a $70 \%$, mantida por meio de nebulização intermitente e a temperatura média variou entre 28 a $32^{\circ} \mathrm{C}$.

Após esse período na casa de vegetação, as mudas foram transferidas para a casa de sombra (sombrite 50\%), onde permaneceram por 15 dias. Nessa fase, receberam $4 \mathrm{ml}$ de fertirrigação por muda/dia $(50 \%$ pela manhã e $5 \%$ à tarde). A solução da fertirrigação foi composta por: $5,5 \mathrm{~kg}$ de $\mathrm{Ca}\left(\mathrm{NO}_{3}\right)_{2} ; 1,5 \mathrm{~kg}$ de $\mathrm{MgSO}_{4} ; 2,63 \mathrm{~kg}$ de $\mathrm{KCl}$; $0,9 \mathrm{~kg}$ de $\mathrm{NH}_{4} \mathrm{H}_{2} \mathrm{PO}_{4} ; 2,0 \mathrm{~kg}$ de $\mathrm{NH}_{4} \mathrm{SO}_{4} ; 0,035 \mathrm{~kg}$ de $\mathrm{H}_{3} \mathrm{BO}_{3} ; 0,004 \mathrm{~kg}$ de $\mathrm{CuSO}_{4} ; 0,015 \mathrm{~kg}$ de $\mathrm{ZnSO}_{4} ; 0,017 \mathrm{~kg}$ de $\mathrm{MnSO}_{4} ; 0,02 \mathrm{~kg}$ de ferrilene; e 2,5 $\mathrm{kg}$ de superfosfato simples, dissolvidos em $1.000 \mathrm{~L}$ de água.

Cerne, Lavras, v. 17, n. 4, p. 601-606, out./dez. 2011 
O experimento foi conduzido em delineamento em blocos casualizados com três repetições, no esquema fatorial $6 \times 2$, sendo estudado o efeito de 6 concentrações de Fert-Bokashi ${ }^{\circledR}(0,0 \%, 0,1 \% ; 0,3 \%$ : 0,5\%; 0,7\% e 0,9\%) e 2 clones (Clone 1 e Clone 2). Cada unidade experimental foi constituída por 120 mudas dispostas em quatro bandejas contendo 190 células cada. Foram mensuradas 30 mudas centrais de cada bandeja e as demais foram consideradas como bordadura. Em todo o experimento foram analisadas 4.320 mudas.

Após a retirada das mudas da casa de sombra, as seguintes características foram avaliadas: sobrevivência $(\%)$, altura $(\mathrm{H}, \mathrm{cm})$, matéria seca da raiz (MSR, gramas por planta), matéria seca da parte aérea (MSPA, gramas por planta) e matéria seca total (MST, gramas por planta). A altura foi mensurada com régua milimetrada a partir da superfície do tubete até o ápice das mudas. O sistema radicular foi lavado em água corrente sobre uma peneira fina para a eliminação do substrato aderido às raizes. Para a avaliação do peso da matéria seca da raiz e da parte aérea, as frações do sistema radicular e da parte aérea foram acondicionadas em sacos de papel e secos em estufa de circulação forçada de ar à $70^{\circ} \mathrm{C}$ até atingir peso constante. Após, efetuou-se a pesagem em balança analítica e calculou-se o peso da matéria seca da raiz, da parte aérea e total por planta.

Os dados foram submetidos à análise de variância e estatística descritiva, utilizando o software Statistica 6.0 (STATSOFT, 2006).

\section{RESULTADOS E DISCUSSÃO}

A precisão do experimento pode ser verificada pelos baixos valores dos coeficientes de variação experimental obtidos para as variáveis analisadas, os quais foram no máximo de $12 \%$. Observou-se, pela ANOVA, que não houve efeito significativo $(p>0,05)$ da interação entre os clones e as concentrações do Fert-Bokashi ${ }^{\circledR}$ e do Fert-Bokashi® sobre as variáveis $\mathrm{H}$, MSPA, MSR e MST aos 28 dias após o estaqueamento, indicando que as concentrações do Fert-Bokashi ${ }^{\circledR}$ aplicadas não influenciaram nas características morfológicas avaliadas. Entretanto, houve diferença estatística $(\mathrm{p}<0,05)$ entre os clones em relação à sobrevivência das mudas.

Os clones avaliados neste estudo foram escolhidos por serem materiais genéticos produtivos e de grande interesse comercial para a empresa, no entanto, apresentam baixos índices de enraizamento que comprometem a sobrevivência das mudas (Tabela 1). Pelos resultados obtidos, torna-se evidente a dificuldade de multiplicação desses materiais genéticos e a pouca eficiência do produto aplicado sobre as variáveis analisadas.

Tabela 1 - Valores médios de sobrevivência das mudas de dois clones de E. urophylla aos 28 dias.

Table 1 - Mean values of seedling survival of two E. urophylla clones at 28 days.

\begin{tabular}{lc}
\hline Material Genético & Sobrevivência (\%) \\
\hline Clone 1 & $63,52 \mathrm{a}$ \\
Clone 2 & $70,51 \mathrm{~b}$ \\
\hline
\end{tabular}

*Médias seguidas por letras diferentes, diferem estatisticamente à $5 \%$ de probabilidade pelo Teste $\mathrm{F}$.

Resultados da aplicação de fertilizantes orgânicos são apresentados por diversos autores. De acordo com Ototumi et al. (2001), a produção de couve-brócolis (Brassica oleraceae L.) não foi influenciada pela aplicação do Bokashi. No entanto, Trani et al. (2006), estudando o efeito de diferentes fertilizantes orgânicos no peso de massa fresca de alface constataram que o Bokashi, juntamente com esterco de frango, apresentaram resultados superiores aos demais tratamentos. Homma (2005), em trabalho realizado com Tangerina Mucorte (Citrus reticulata, Blanco x Citrus sinensis, Osbeck), observou efeito positivo da aplicação de Bokashi para diversos parâmetros avaliados, como resistência do solo à penetração, densidade radicular superficial, colonização de fungos micorrízicos arbusculares nativos, análise de conteúdo de nutriente foliar, produtividade e qualidade do fruto.

No presente trabalho, quanto ao Clone 1, observouse que a aplicação de $0,1 \%$ de Fert-Bokashi ${ }^{\circledR}$ resultou em acréscimo de $12,5 \%$ no percentual de sobrevivência das mudas em relação à testemunha. Resultado oposto foi observado para o clone 2, onde a testemunha obteve a maior porcentagem de sobrevivência (Figura 1).

Para a variável altura das plantas, a aplicação de $0,1 \%$ proporcionou um acréscimo de $7,0 \%$ e $5,5 \%$ em relação ao tratamento sem o Fert-Bokashi®, para os clones 1 e 2, respectivamente (Figura 2).

Em trabalho realizado com melão amarelo (Cucumis melo), Gomes et al. (2007) verificaram que na primeira medição de altura não houve diferença siginificativa entre os tratamentos que receberam o composto orgânico Bokashi quando comparados aos que não receberam.

Cerne, Lavras, v. 17, n. 4, p. 601-606, out./dez. 2011 


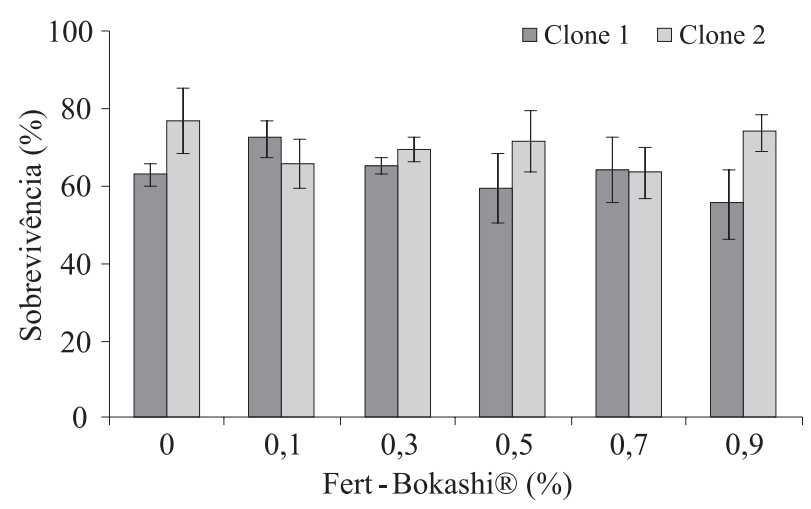

Figura 1 - Valores de sobrevivência das mudas de dois clones de E. urophylla em resposta à aplicação de Fert-Bokashi ${ }^{\circledR}$, aos 28 dias. As barras indicam o desvio padrão.

Figure 1 - Values of seedlings survival of two E. urophylla clones in response to Fert-Bokashi ${ }^{\circledR}$ application, at 28 days. Bars indicate the standard deviation.

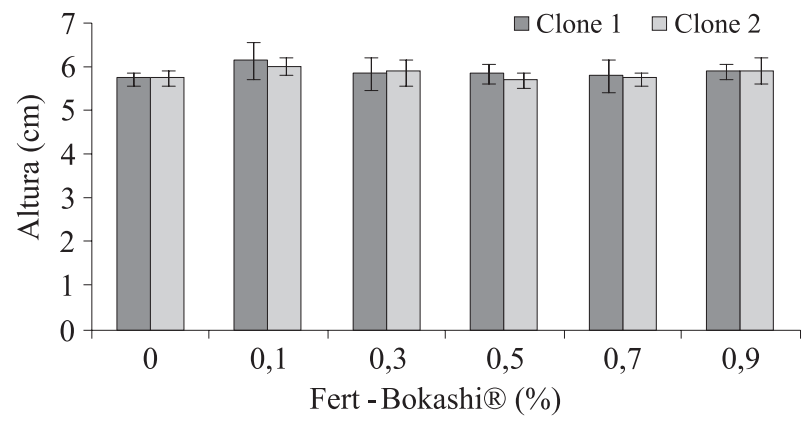

Figura 2 - Valores de altura das mudas dos clones de E. urophylla em resposta à aplicação de Fert-Bokashi ${ }^{\circledR}$, aos 28 dias. As barras indicam o desvio padrão.

Figure 2 - Values of seedlings height of E. urophylla clones in response to Fert-Bokashi $\AA^{\circledR}$ application, at 28 days. Bars indicate the standard deviation.

Porém, aos 25 dias, a altura média verificada nos tratamentos com o Bokashi já diferiram significamente em relação aos demais tratamentos. Essa diferença se manteve ao longo dos 32 dias de transplantio, sendo que a maior concentração utilizada foi a que proporcionou os melhores resultados. Em contraposição, Augusto et al. (2007) avaliaram o efeito de águas residuárias de esgoto sobre mudas de Eucalyptus grandis em fertirrigação, constatando que para a altura, massa seca radicular e massa seca da parte aérea o tratamento convencional foi superior ao tratamento com águas residuárias, sendo que a superioridade apresentada foi de $120,1 \%$ para massa seca da parte aérea e 38,6\% para a massa seca radicular. Esses autores sugeriram que os resultados foram obtidos, provavelmente, pelo tratamento convencional, apresentando maior concentração de macronutrientes na solução nutritiva em relação à água residuária.

No presente experimento, observou-se ligeira queima e início de murcha das mudas nos tratamento de maior concentração de Fert-Bokashi® $(0,9 \%)$, quando se avaliou a altura aos 28 dias. Nos demais tratamentos, as mudas apresentavam aspecto saudável. Esse fato pode ser decorrente de um possível efeito de toxidez às plantas em concentrações maiores do produto.

Em relação à matéria seca da parte aérea, para o clone 1 a maior média $(0,096 \mathrm{~g} / \mathrm{planta})$ foi obtida no tratamento sem o Fert-Bokashi ${ }^{\circledR}$, enquanto a menor foi obtida com a maior concentração do produto $(0,081$ $\mathrm{g} /$ planta). Para o clone 2, observou-se aumento da massa seca na medida em que se aumentou a concentração até $0,3 \%$, sendo, posteriormente, observado decréscimo dos valores (Figura 3).

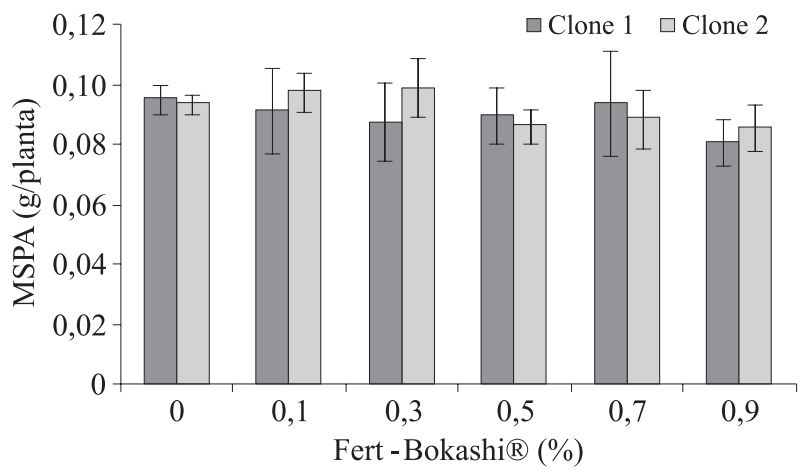

Figura 3 - Valores de matéria seca da parte aérea (MSPA) das mudas dos clones de E. urophylla em resposta à aplicação de Fert-Bokashi ${ }^{\circledR}$, aos 28 dias. As barras indicam o desvio padrão.

Figure 3 - Values of seedling shoot dry matter (MSPA) of E. urophylla clones in response to Fert-Bokashi ${ }^{\circledR}$ application, at 28 days. Bars indicate the standard deviation.

Quanto à matéria seca da raiz, foi observado um acréscimo com o aumento das concentrações do Fert-Bokashi ${ }^{\circledR}$ para o clone 1, sendo as maiores médias obtidas nas concentrações $0,5 \%$ e $0,9 \%(0,031 \mathrm{~g} /$ planta $)$. A menor média foi obtida no tratamento sem a aplicação do produto $(0,027 \mathrm{~g} /$ planta $)$. Para o clone 2 , essa tendência também foi observada, com maior peso de matéria seca de raiz obtida na concentração de $0,7 \%(0,031 \mathrm{~g} /$ planta $)$, sendo, posteriormente, observado um decréscimo na

Cerne, Lavras, v. 17, n. 4, p. 601-606, out./dez. 2011 
concentração de $0,9 \%$. A menor média $(0,025 \mathrm{~g} / \mathrm{planta})$ novamente foi observada quando não se aplicou o produto. Com base nesses resultados, constatou-se um acréscimo de aproximadamente $15 \%$ e $24 \%$ no peso de matéria seca radicular para o clone 1 e clone 2 , respectivamente, em relação a não aplicação do produto (Figura 4).

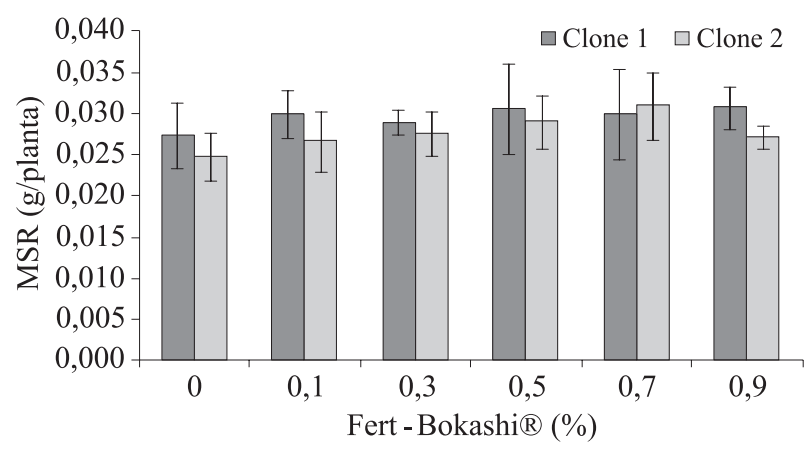

Figura 4 - Valores de matéria seca de raiz (MSR) das mudas dos clones de E. urophylla em resposta à aplicação de Fert-Bokashi ${ }^{\circledR}$, aos 28 dias. As barras indicam o desvio padrão.

Figure 4 - Values of seedling root dry matter (MSR) of E. urophylla clones in response to Fert-Bokashi ${ }^{\circledR}$ application, at 28 days. Bars indicate the standard deviation.

De acordo com a Figura 5, observa-se que o maior peso de matéria seca total para o clone 1 foi encontrado na concentração de $0,7 \%(0,124 \mathrm{~g} /$ planta $)$ e o menor na concentração de $0,9 \%(0,112 \mathrm{~g} /$ planta $)$. Para o clone 2 , o maior valor foi obtido a $0,3 \%$ de Fert-Bokashi ${ }^{\circledR}(0,127$ $\mathrm{g} /$ planta) e o menor valor novamente na concentração de $0,9 \%$ do produto $(0,113 \mathrm{~g} /$ planta $)$.

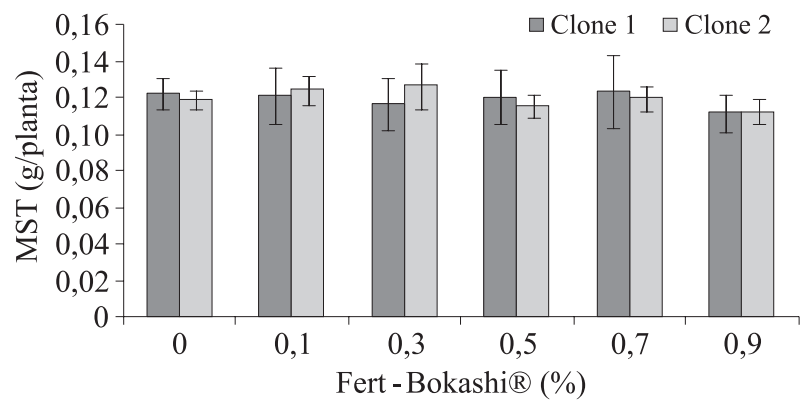

Figura 5 - Valores de matéria seca total (MST) das mudas dos clones de E. urophylla em resposta à aplicação de Fert-Bokashi ${ }^{\circledR}$, aos 28 dias. As barras indicam o desvio padrão.

Figure 5 - Values of seedling total dry matter (MST) of E. urophylla clones in response to Fert-Bokashi ${ }^{\circledR}$ application, at 28 days. Bars indicate the standard deviation.
Homma (2005) não observou diferenças significativas em análises da densidade superficial radicular de massa seca e massa fresca de Tangerina Mucorte (Citrus reticulata, Blanco x Citrus sinensis, Osbeck) para tratamentos com Bokashi, em relação ao tratamento convencional. Porém, quando imagens processadas pelo SIARCS foram analisadas, as plantas do tratamento com Bokashi demonstraram maior área espacial (56,1\% maior) e maior comprimento de raízes $(26,9 \%$ maior) quando comparadas com o tratamento convencional. Oliveira et al. (2010), trabalhando com enraizamento de estacas de duas cultivares de oliveira (Olea europaea L.), submetidas à aplicação de diferentes fertilizantes orgânicos, não observaram diferença significativa entre o tratamento com Fert Bokashi e o Controle para as características de percentual de estacas enraizadas e comprimento médio de raízes. No entanto, o Biofertilizante apresentou superioridade para o percentual de enraizamento, número médio e comprimento médio de raízes, sendo indicado como de uso potencial para o enraizamento de estacas da espécie, podendo auxiliar na redução dos custos de produção de mudas.

\section{CONCLUSÕES}

Considerando as condições em que o experimento foi conduzido, concluiu-se que o fertilizante orgânico Fert-Bokashi® não exerceu efeito significativo sobre a sobrevivência e o crescimento das mudas dos dois clones de Eucalyptus urophylla.

\section{AGRADECIMENTOS}

À Empresa Plantar Reflorestamentos S.A., pela disponibilização do material genético (clones) e pelo suporte físico e financeiro.

\section{REFERÊNCIAS}

ALFENAS, A. C.; ZAUZA, E. A. V.; MAFIA, R. G.; ASSIS, T. F. Clonagem e doenças do eucalipto. Viçosa, MG: UFV, 2004. 442 p.

ASSIS, T. F. Propagação vegetativa de Eucalyptus por microestaquia. In: IUFRO CONFERENCE ON SILVICULTURE AND IMPROVEMENT OF EUCALYPTS, 1997, Salvador.

Proceedings... Colombo: Embrapa, 1997. p. 300-304.

AUGUSTO, D. C. C.; GUERRINI, I. A.; ENGEL, V. L.; ROUSSEAU, G. X. Utilização de águas residuárias provenientes do tratamento biológico de esgotos domésticos na produção de Eucalyptus grandis Hill. ex. maiden. Revista Árvore, Viçosa, v. 31, n. 4, p. 745-751, jul./ago. 2007.

Cerne, Lavras, v. 17, n. 4, p. 601-606, out./dez. 2011 
BOTREL, N.; RESENDE, F. V.; GUIMARÃES, M. O.; ALVES, R. F. Qualidade pós-colheita de abobrinha italiana produzida em sistema orgânico com composto de farelos, tipo Bokashi ${ }^{\circledR}$. Revista Brasileira de Agroecologia, Brasília, v. 2, n. 2, p. 12-16, out. 2007.

GOMES, V. F. F.; MAIA, A. M.; NESS, R. L. L.; GUIMARÃES, V. A. Influência do Bokashi no desenvolvimento do melão e na atividade microbiana de um neossolo quartzarênico. In: CONGRESSO BRASILEIRO DE CIÊNCIAS DO SOLO, 31., 2007, Gramado. Anais... Viçosa, MG: SBCS, 2007. p. 139.

HOMMA, S. K. de. Efeito do manejo alternativo sobre a descompactação do solo, fungos micorrízicos arbusculares nativos e produção em pomar convencional Tangor 'Murcott'. 2005. 101 p. Dissertação (Ecologia de Agrossistemas) - Escola Superior de Agricultura "Luiz de Queiroz", Piracicaba, 2005.

KHATOUNIAN, C. A.; SANTOS, L. G. de C.; ALTÉIA, A. A. K. Produção orgânica de hortaliças. Londrina: IAPAR, 1996.

OLIVEIRA, M. C.; VIEIRA NETO, J.; OLIVEIRA, R. S.; PIO, R.; OLIVEIRA, N. C.; RAMOS, J. D. Enraizamento de estacas de duas cultivares de Oliveira submetidas à aplicação de diferentes fertilizantes. Bragantia, Campinas, v. 69, n. 1, p. 99-103, mar. 2010.

OTOTUMI, A.; VENTURA, M. U.; NEVES, P. M. O. J. Parâmetros agronômicos em couve-brócolos (Brassica oleraceae L. var. Italica) em sistema convencional, orgânico e natural. Semina: Ciências Agrárias, Londrina, v. 22, n. 2, p. 161-164, jul./dez. 2001.
STATSOFT. Statistica: data analysis software system. Version 6. New York, 2006. Software.

TITON, M.; XAVIER, A.; OTONI, W. C. Clonal propagation of Eucalyptus grandis using the mini-cutting and microcutting techniques. Scientia Forestalis, Piracicaba, n. 71, p. 109-117, ago. 2006.

TITON, M.; XAVIER, A.; OTONI, W. C.; REIS, G. G. Efeito do AIB no enraizamento de miniestacas e microestacas de clones de Eucalyptus grandis W. Hill ex Maiden. Revista Árvore, Viçosa, v. 27, n. 1, p. 1-7, jan./fev. 2003a.

TITON, M.; XAVIER, A.; REIS, G. G.; OTONI, W. C. Eficiência das minicepas e microcepas na produção de propágulos de clones de Eucalyptus grandis. Revista Árvore, Viçosa, v. 27, n. 5, p. 619-625, set./out. 2003b.

TRANI, P. E.; BOVI, O. A.; TAMISO, L. G.; BERTON, R. S.; ABRAMIDES, P. L. Produção orgânica de hortaliças e medicinal sob cultivo protegido. Disponível em: $<$ http:// www.infobibos.com/Artigos/2006_2/ProdOrganica/index. htm>. Acesso em: 10 dez. 2006.

XAVIER, A.; ANDRADE, H. B.; OLIVEIRA, M. L.; WENDLING, I. Desempenho do enraizamento de microestacas e miniestacas de clones híbridos de Eucalyptus grandis. Revista Árvore, Viçosa, v. 25, n. 4, p. 403-411, jul./ ago. 2001.

XAVIER, A.; COMÉRIO, J. Microestaquia: uma maximização da micropropagação de Eucalyptus. Revista Árvore, Viçosa, v. 20, n. 1, p. 9-16, jan./fev. 1996.

Cerne, Lavras, v. 17, n. 4, p. 601-606, out./dez. 2011 